\title{
Personalizing Child Protection: The Value of Responsivity Factors
}

\author{
Anne M. E. Bijlsma * (D), Claudia E. van der Put, Geertjan Overbeek, Geert Jan J. M. Stams and Mark Assink $\mathbb{D}$ \\ Research Institute of Child Development and Education, University of Amsterdam, \\ 1018 WS Amsterdam, The Netherlands; C.E.vanderPut@uva.nl (C.E.v.d.P.); G.J.Overbeek@uva.nl (G.O.); \\ G.J.J.M.Stams@uva.nl (G.J.J.M.S.); M.Assink@uva.nl (M.A.) \\ * Correspondence: A.M.E.Bijlsma@uva.nl
}

Citation: Bijlsma, Anne M. E., Claudia E. van der Put, Geertjan Overbeek, Geert Jan J. M. Stams, and Mark Assink. 2021. Personalizing Child Protection: The Value of Responsivity Factors. Social Sciences 10: 205. https://doi.org/10.3390/ socsci10060205

Academic Editor: Nigel Parton

Received: 30 April 2021

Accepted: 28 May 2021

Published: 31 May 2021

Publisher's Note: MDPI stays neutral with regard to jurisdictional claims in published maps and institutional affiliations.

Copyright: (c) 2021 by the authors. Licensee MDPI, Basel, Switzerland. This article is an open access article distributed under the terms and conditions of the Creative Commons Attribution (CC BY) license (https:/ / creativecommons.org/licenses/by/ $4.0 /)$.

\begin{abstract}
Personalization is an important strategy for enhancing the effectiveness of treatment that is aimed at reducing the risk of child maltreatment. In recent years, a growing body of research has appeared on how child protection can benefit from the principles of the Risk-Need-Responsivity model, but no attention has yet been paid to the implementation of the responsivity principle in child protection. Put simply, this principle states that treatment must be tailored to individual characteristics of clients to optimize its effectiveness. This study was the first to address how the responsivity principle can be of value in child protection. First, a systematic review of responsivity factors in forensic care was performed. Second, the relevance of applying each factor in child protection was examined through interviews with clinical professionals working in the field, who also provided suggestions on how treatment can be tailored to each of these factors. This resulted in an overview of seven responsivity factors all related to caregiver characteristics: problem denial, motivation to cooperate with treatment, psychological problems, cognitive abilities, cultural background, practical barriers such as financial problems and social support, and barriers to specific treatment types such as group therapy. Implications and recommendations for strengthening clinical practice are discussed.
\end{abstract}

Keywords: child protection; RNR-model; responsivity; caregiver characteristics

\section{Introduction}

Child maltreatment is a worldwide public health problem with serious long-term consequences for the development of millions of children (e.g., English et al. 2005; Gilbert et al. 2009; Stoltenborgh et al. 2015). Therefore, effective intervention programs for reducing the risk are highly needed. Throughout the years, a wide range of parent support programs aimed at reducing (the risk of) child maltreatment have been developed, but the actual effects of these programs are still only small to modest (Euser et al. 2015; Van der Put et al. 2018a; Vlahovicova et al. 2017).

The effectiveness of parenting programs that target maltreatment can probably be enhanced by tailoring these programs to the individual needs and characteristics of caregivers (Ng and Weisz 2016; Weisz 2014). A way to facilitate such personalized intervention in child protection is through applying the Responsivity principle from the Risk Need Responsivity model of effective judicial interventions (Andrews et al. 1990), which enables reduction of barriers to treatment participation, and optimization of treatment circumstances. Recently, researchers argued that the RNR principles can also be applied to child protection services in order to enhance the effectiveness of treatment aimed at reducing the risk of (recurring) child maltreatment (e.g., Van der Put et al. 2016b, 2018a). However, studies examining how the Responsivity principle of the RNR model can be implemented in the field of child protection are not yet available. Therefore, this study aimed to (1) identify an overview of responsivity factors in criminal practice with criminal offenders and (2) examine the value of targeting these factors in the clinical field of child protection, and how those factors can be targeted to enhance caregivers' abilities to succeed in treatment. 
Tailoring treatment and interventions to the individual (specific) needs and characteristics of clients has been addressed in different forms of public health care. In forensic care aimed at preventing criminal recidivism, personalizing treatment has been largely guided by the Risk Need Responsivity model (Andrews et al. 1990). This model prescribes how treatment should be tailored to individuals, based on three core principles: (1) the Risk principle assumes that the program intensity level should be matched to the offender's risk of criminal recidivism; (2) the Need principle assumes that the offender's criminogenic needs (i.e., changeable risk factors associated with criminal recidivism) should be targeted; and (3) the Responsivity principle assumes that interventions should be matched to the offender's learning style and abilities.

According to the general responsivity principle, cognitive social learning methods (e.g., prosocial modeling and problem solving) should be used to influence behavior. The specific responsivity principle states that strategies should be modified in accordance with the learning ability, learning style, circumstances, and demographic characteristics of individual cases, such as gender, age, and ethnicity (Andrews et al. 2011; Bonta and Andrews 2007, 2016). Interventions adhering to all three principles of the RNR model reduce offender recidivism more effectively than interventions not adhering to the RNR principles (e.g., Andrews et al. 1990; Hanson et al. 2009).

Although the RNR model has been developed specifically for effective prevention of criminal behavior, it seems highly promising to apply the RNR principles in child protection to personalize systematic (family) interventions and to effectively prevent child maltreatment (Mulder et al. 2018; Van der Put et al. 2016b, 2018a). Both delinquency and child maltreatment can be explained by the interplay of risk factors (e.g., psychopathology) and protective factors (e.g., social support) in various social systems, such as the family, school, and neighborhood (see Bronfenbrenner 1979). Furthermore, occurrence of delinquency and child abuse are determined by the balance between risk and protective factors (Belsky 1980, 1984; Cicchetti and Carlson 1989; Cicchetti and Rizley 1981; Folger and Wright 2013; Smith et al. 2009; Stouthamer-Loeber et al. 2002). To effectively stop criminal behavior and child maltreatment, risk factors need to be addressed as described in the RNR framework.

Until now, the RNR principles have been applied to the clinical practice of child protection only to a limited extent. In recent years, the first structured instruments for child protection services became available that facilitate the implementation of the risk and need principles in child protection (Van der Put et al. 2016a, 2018b; De Ruiter et al. 2012). However, studies examining to what extent the responsivity principle is implemented in the field of child protection are not yet available. This is striking, given that responsivity is one of the three core components of the RNR framework that prescribes how interventions should be tailored to the individual needs and characteristics of clients and thus delivered in a personalized way (Bonta and Andrews 2016). Applying the responsivity principle in child protection may be just as important as in forensic care, because in general, without adhering to the responsivity principle, even well-designed programs can be ineffective by failing to remove or reduce significant barriers to treatment participation (Covell and Wheeler 2011).

The original conceptualization of the Responsivity principle assumes that interventions should contain cognitive social learning methods, and that intervention should be tailored to the learning style, motivation, abilities, and strengths of the offender (Bonta and Andrews 2016). Another conceptualization has been made by Ogloff and Davis (2004), who focus more on multiple responsivity impediments, such as a lack of motivation, which moderate treatment effects, and therefore should be addressed prior to targeting the client's needs (Ogloff and Davis 2004; Ward et al. 2007). Looman et al. (2005) described general responsivity more specifically as external factors, and specific responsivity as internal factors. External factors refer to contextual factors that affect treatment outcomes (e.g., therapist/social worker characteristics and characteristics of the treatment setting), whereas internal factors refer to personal factors of a client (e.g., psychopathy and motivation) 
(Looman et al. 2005). It has also been suggested that responsivity is a function of both internal and external factors, which may interact (Howells and Day 2007).

Responsivity also relates to the degree to which an intervention is appropriate given the unique characteristics of a client. As interventions are less aligned with these characteristics, the effectiveness of treatment declines (Taxman 2014). For example, an anxious client may not respond well to group interventions (Smith et al. 2009). Further, poorly motivated offenders may become more engaged in treatment when they better understand how an intervention serves their interests (Polaschek 2012). Just as in forensic care, engagement of children's caretakers in child protection services is important for enhancing intervention outcomes, of which child safety is a crucial one (Cunningham and Henggeler 1999; Platt 2012). Besides treatment engagement, there are many other barriers to successful intervention outcomes in child welfare, such as mental illness or substance abuse (Dawson and Berry 2002). Such factors may have a negative impact on the outcome of protocolled treatment programs if these programs are not specifically designed to target such factors (Van Yperen et al. 2017). However, it would be possible to allow flexibility in delivering an intervention program based on identified treatment barriers using the right approaches.

In their latest research on specific responsivity, Bonta and Andrews (2016) have emphasized the identification of personal client factors, such as interpersonal sensitivity, anxiety, verbal intelligence, and cognitive maturity, to further improve individual treatment matching. They also underline the importance of motivation as a responsivity factor, which should be increased to prevent treatment drop out (Bonta and Andrews 2016). Hubbard (2007) also argues that such personal characteristics of offenders may interfere with their ability to succeed in treatment. To enhance program effectiveness, such characteristics must be addressed through assessment prior to treatment (Hubbard 2007). However, due to the widely diverging views on how responsivity should be defined, there is no consensus in scientific literature on how responsivity factors should be operationalized and assessed (Hubbard 2007). For example, motivation and participation-which are aspects of treatment readiness-have been introduced to reflect treatment responsivity in treatment settings (Howells and Day 2003; Mossière and Serin 2013). Additionally, client characteristics such as self-efficacy, problem-recognition, and perceived coercion, are other relevant aspects in responsivity assessments (Day et al. 2009; Loza et al. 2000).

For interventions to be effective, it is crucial for practitioners to tailor interventions to the client in the best possible way, which requires a comprehensive overview of responsivity factors. Therefore, the aim of this study is to provide such an overview by reviewing literature on responsivity factors in criminal practice with criminal offenders, and by examining the value of those factors in child protection through interviews with clinical professionals.

\section{Methods}

\subsection{Literature Review of Responsivity Factors in Criminal Practice}

\subsubsection{Inclusion Criteria}

For identifying relevant responsivity factors, (forensic) responsivity and treatment readiness assessment instruments were searched for and retrieved from multiple databases. The keywords that were used in this search for articles, reports, book chapters, and manuals on responsivity assessment are presented in Figure 1. Only studies written in Dutch and English of which the full text could be retrieved were included. As a form of quality control, studies had to be published in peer-reviewed scientific journals or be (part of) a dissertation that was accessible to the authors of this review. Publication year was not an inclusion criterion. 


\section{PsycINFO \\ Ovid}

\section{\#1 responsivity instruments}

(correctional treatment* scale* OR change assessment* OR client management classification OR ((client motivation OR motivation readiness OR motivation to change OR offender readiness OR offender motivation $O R$ readiness to change $O R$ responsivity $O R$ treatment eagerness $O R$ treatment engagement $O R$ treatment motivation $O R$ treatment readiness $O R$ want to change $O R$ willing* to change) $\mathrm{ADJ} 3$ (assess* $\mathrm{OR}$ instrument* $\mathrm{OR}$ measure* $\mathrm{OR}$ questionnaire* $\mathrm{OR}$ rating $\mathrm{OR}$ scale* $\mathrm{OR}$ test ${ }^{*}$ OR tool*)) OR helping alliance rating method* OR treatment readiness interview* OR ohio scales OR URICA OR VTRQ OR SOCRATES).ti.ab.id.tm. OR (responsivity).tm.

\section{\#2 child welfare}

child care workers/OR child welfare/ OR counselors/OR protective services/OR social workers/OR social casework/ OR "Welfare Services (Government)"/ OR Social Services/ OR Community Welfare Services/ OR counseling/ OR group counseling/OR rehabilitation counseling/OR (casework* OR child care $O R$ child welfare $O R$ counsel* $O R$ frontline $O R$ protective service* $O R$ social work* $O R$ youth care OR youthcare).ti.ab.id.

\section{\#3 criminology}

addiction/ OR child abuse/ OR child neglect/ OR correctional institutions/ OR crime/ OR criminal behavior/OR criminals/OR criminology/OR domestic violence/ OR drug addiction/ OR forensic psychiatry/OR forensic psychology/OR incarceration/ OR incest/ OR intimate partner violence/ OR juvenile delinquency/OR juvenile justice/ OR kidnapping/OR mentally ill offenders/OR partner abuse/ OR pedophilia/ OR perpetrators/OR prisons/ OR prisoners/ OR recidivism/ OR rape/ OR sex offenses/ OR (addict* OR child abuse OR child molest* OR child neglect OR child pornography $O R$ crime* $\mathrm{OR}$ criminal* $\mathrm{OR}$ convicts $\mathrm{OR}$ correctional* $\mathrm{OR}$ delinquen* $\mathrm{OR}$ domestic violence $\mathrm{OR}$ forensic OR incarcerat* OR incest* OR juvenile justice OR kidnap* OR offender* OR paedo* $O R$ partner abus* $O R$ partner violence $O R$ pedo* $O R$ perpetrator* $O R$ prison* $O R$ rape $O R$ rapist $O R$ rearrest* $O R$ recidiv* $O R$ reconvict* $O R$ re-convict* $O R$ reincarcerat* $O R$ re-incarcerat* $O R$ reoffen* OR re-offen* ${ }^{*}$ R sex* offen*).ti.ab.id.

1 AND (2 OR 3) 655 results

Figure 1. Search Query.

\subsubsection{Search Strategy}

Results were retrieved from the following databases: PsycInfo (655 results), Web of Science (282 results), Medline (217 results), and Social Services Abstracts (148 results). Additionally, we performed an orientation search with records from Google Scholar (229 results). Database search results were checked for eligibility with RefWorks, in which duplicates were checked and removed (Figure 2). In the screening phase, a first selection of relevant results was made based on titles and abstracts in the program Rayyan QCRI. In the eligibility phase, 434 articles were evaluated by reading the full text, after which 51 different instruments were identified. Some instruments were excluded, because they were identical to other instruments with a different name, or because they were specifically designed to be used in a single study.

Based on the results of the responsivity literature search, an overview of responsivity factors primarily related to caregiver characteristics in child protection services was drafted. This included the following factors: problem denial (derived from the factor: criminal thinking and responsibility), treatment motivation/willingness to cooperate (derived from the factors: program perceptions and motivation), psychological functioning, cognitive abilities and culture (derived from the factor: biosocial), practical barriers/social support, and barrier to treatment program type (derived from the factor: self-disclosure). Every factor on the list included a description to ensure that factors were not ambiguously interpreted. 


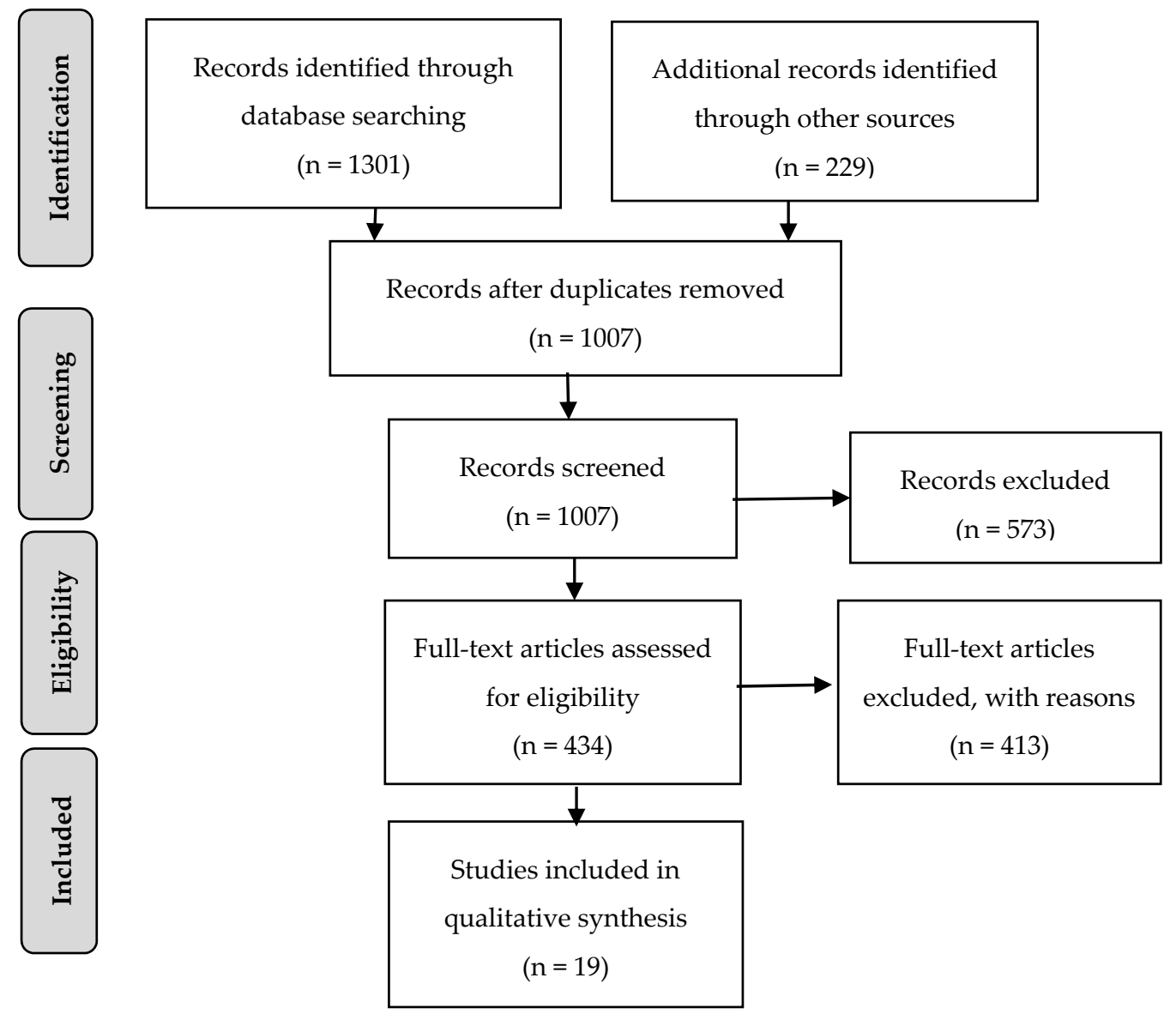

Figure 2. Flow Diagram of Included Studies.

\subsection{Interviews on the Practical Relevance of Responsivity Factors in Child Protection}

\subsubsection{Participants}

Semi-structured interviews were conducted with 14 professionals working in the field of child protection, specifically in health care institutions offering care to families. The professionals had a variety of occupations, including: two behavioral scientists, four (ambulatory) social workers, one advisor of the Board of Child Protection, one school psychologist, two clinical psychologists, one pediatrician, one post-master's healthcare psychologist, one remedial educationist, and one interactive child therapist. Since all professionals had a certain degree of expertise in the domain of inquiry, a sufficient degree of data saturation could be assumed (Guest et al. 2006).

\subsubsection{Procedure}

Professionals were recruited by contacting the organizations that participate in the consortium research project that resulted in the current study, and through flyers that were distributed among the authors' professional network. The professionals who agreed to participate received detailed information on research participation, after which the interview was scheduled. Semi-structured interviews with a duration of approximately one hour were conducted by two interviewers at a time, usually the first author along with a master's degree student. Prior to conducting the interviews, the students were thoroughly instructed about the interview procedure. The interviews took place at the workplace of the participant and were digitally recorded. Professionals were asked for permission to record the interview and informed that all personal data was anonymized for this study. Participants signed an informed consent prior to the interview, and received a voucher of 25 euros for their cooperation afterwards. 


\subsubsection{Interview}

The interview started with general questions about the participant's understanding of the responsivity principle of the RNR model (Andrews et al. 1990): (1) What is responsivity, and what factors are related to responsive treatment delivery? Next, the overview of responsivity factors was presented, and each factor was evaluated separately with the following questions: (2) Do you consider this factor relevant within the field of child protection? and (3) How can the factor and its explanation be improved? Then, we asked about treatment suggestions for tailoring treatment to identified responsivity factors: (4) Which specific treatment techniques would you use when this factor applies for your client? Prior to the interviews, a pilot interview was held after which the questionnaire was adjusted and finalized.

\subsubsection{Data Analysis}

The recordings of the interviews were transcribed, and then analyzed with the software program ATLAS.ti according to the guidelines of Boeije (2014). During the open coding stage of the first interviews, themes were gathered in code groups for which a coding scheme was formed. Examples of these code groups are: 'understanding of responsivity (factors)', 'concluding judgments', 'missing factors', and 'relevance of each factor'. New codes were formed, or existing codes were merged with corresponding codes in the selective coding stage. All interviews were double coded and compared, which resulted in a total of 449 codes divided into 25 code groups. For all code groups, networks were created to provide an overview of relations between codes. These networks provided insight into the contradictions and similarities between different codes. Figure 3 shows an example of a network of interrelated suggestions for cultural/ethnical treatment adaptations. The codes are categorized by color, and the arrows illustrate the associations between the codes (i.e., 'associated with' or 'being a part of'). For example, the code 'being sensitive' is centrally associated with 'having a friendly and open attitude', 'showing understanding of cultural values', and 'not being judgmental'.

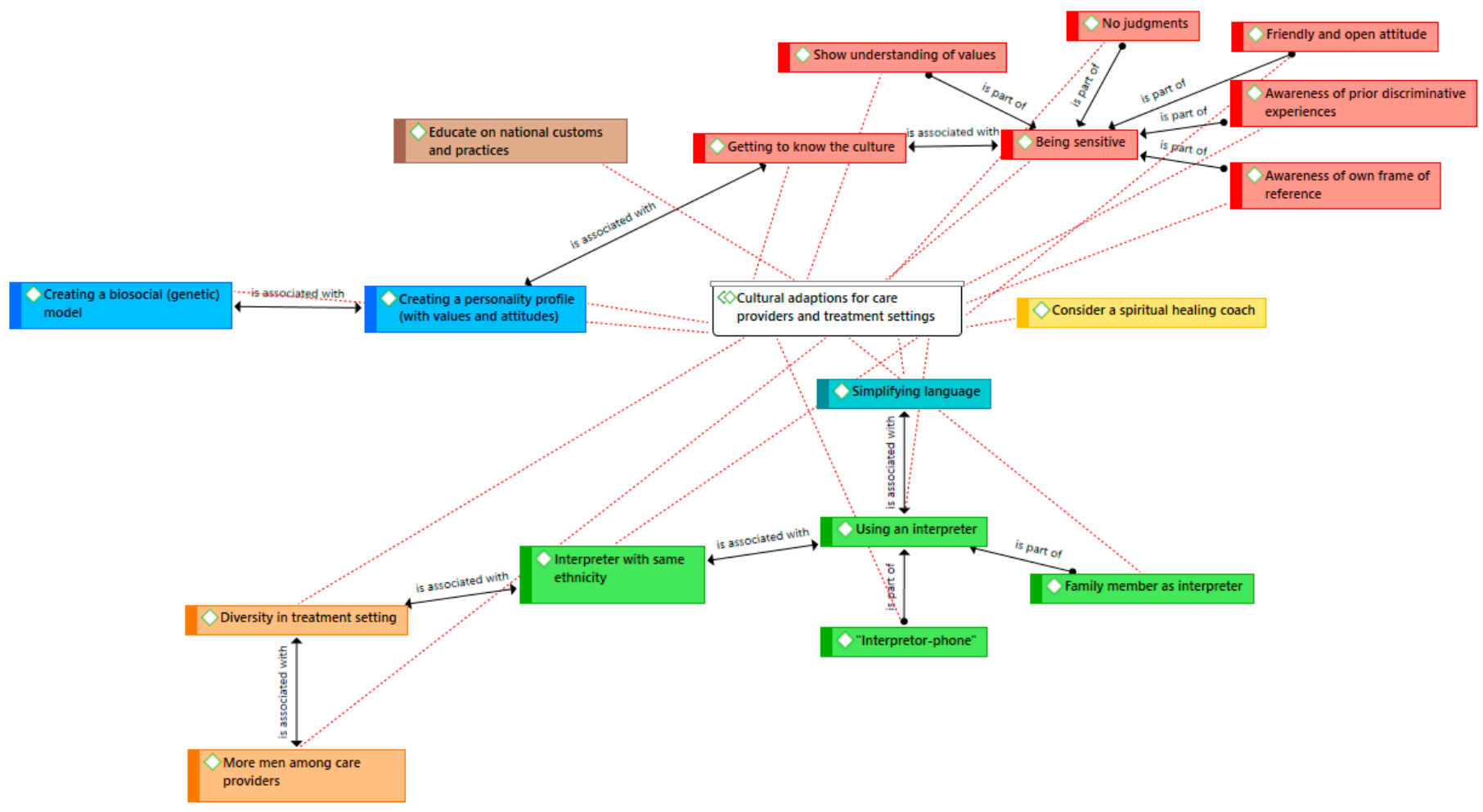

Figure 3. Network Example: Treatment Suggestions for Cultural Adaptions. 


\section{Results}

\subsection{Literature Review of Responsivity Factors in Criminal Practice}

Table 1 provides an overview of the 19 instruments that were retrieved, with the responsivity factors that are assessed with these instruments. Based on these factors, seven responsivity categories were identified, which are reflected by the column headings of Table 1. Motivation was the most frequently measured responsivity aspect, operationalized in terms of treatment readiness, readiness to change, treatment engagement, internal- and external motivation, and stages of change. Other frequently measured responsivity aspects were: criminal thinking and responsibility (e.g., problem denial), program perceptions (e.g., confidence in treatment), and psychological functioning.

\subsection{Interviews on the Practical Relevance of Responsivity Factors in Child Protection and Clinical Treatment Suggestions}

\subsubsection{Understanding of the Responsivity Principle}

Only two participants, who both work in forensic institutions, were familiar with the RNR-model, and the 'what works' principles in daily practice. Four participants were not at all familiar with the concept of responsivity. Three participants thought that responsivity refers to responsiveness and sensitivity of parents to their children. Other participants defined responsivity as 'thinking about a right approach', or 'connecting to someone's potentials'. After the explanation of the responsivity principle, participants named several factors related to responsive treatment delivery: cognitive abilities (six), culture/ethnicity (six), socioeconomic factors (four), psychopathology (three), motivation (two), willingness to cooperate (two), trust (two), personality (one), parental stress (one), resistance (one), and relationship problems (one).

An overview of factor explanations and treatment suggestions from participants for tailoring treatment to the responsivity factors can be found in Table 2.

\subsubsection{Problem Denial}

Two participants suggested that the explanation of problem denial should also include problem justification/excuse. Further, two professionals noted that client denial could also be client unawareness ("We as care providers can label something as child maltreatment, but a client can have different standards, due to a different background.").

Treatment Suggestions. Most clinical treatment suggestions were about improving the therapeutic relationship, by which trust should be earned before problems are discussed. Further, it may be important to use general conversational starting points during the first contact moments that can be extended to other (problem) areas. Frequent contact with the client may also be necessary to allow time for the acceptance process of concerns. Problems can be addressed with a more direct approach, but without any judgement. Other suggestions were focusing on possibilities, and creating a 'positive life plan' with concrete steps. 
Table 1. Operationalization of Responsivity Factors.

\begin{tabular}{|c|c|c|c|c|c|c|c|}
\hline Instruments & $\begin{array}{l}\text { Criminal Thinking } \\
\text { and Responsibility }\end{array}$ & Program Perceptions & Motivation & Social Support & Self-Disclosure & Personality & Biosocial \\
\hline $\begin{array}{l}\text { - Texas Christian University } \\
\text { (TCU) Short Forms for } \\
\text { Assessing Client Needs and } \\
\text { Functioning } \\
\text { (Simpson et al. 2012) }\end{array}$ & $\begin{array}{l}\text { Criminal thinking and } \\
\text { cognitive orientation }\end{array}$ & & $\begin{array}{l}\text { Motivation and } \\
\text { readiness for treatment }\end{array}$ & $\begin{array}{l}\text { Social relations and } \\
\text { functioning }\end{array}$ & & $\begin{array}{l}\text { Psychological } \\
\text { functioning }\end{array}$ & \\
\hline $\begin{array}{l}\text { - } \quad \text { Revised Safe at Home } \\
\text { Instrument } \\
\text { (Begun et al. 2008) }\end{array}$ & & & Readiness to change & & & & \\
\hline $\begin{array}{l}\text { - Treatment Engagement } \\
\text { Rating Scale (Drieschner and } \\
\text { Boomsma 2008) }\end{array}$ & & Openness & $\begin{array}{l}\text { Efforts to change } \\
\text { behavior }\end{array}$ & & & & \\
\hline $\begin{array}{ll}\text { - } & \text { (C)VTRQ \& Violence } \\
\text { Treatment Readiness } \\
\text { Interview (Casey et al. 2007) }\end{array}$ & $\begin{array}{c}\text { Offending } \\
\text { beliefs/Responsibility }\end{array}$ & Program attitudes & $\begin{array}{l}\text { Motivation (Desire to } \\
\text { change) }\end{array}$ & & $\begin{array}{c}\text { Self-confidence/Group } \\
\text { progress }\end{array}$ & Emotional responses & \\
\hline $\begin{array}{l}\text { - } \quad \text { Criminal Justice Client } \\
\text { Evaluation of Self and } \\
\text { Treatment } \\
\text { (Garner et al. 2007) }\end{array}$ & Criminal thinking & $\begin{array}{l}\text { Treatment } \\
\text { participation and } \\
\text { satisfaction }\end{array}$ & $\begin{array}{l}\text { Treatment motivation } \\
\text { and engagement }\end{array}$ & Social and peer support & Self-esteem & $\begin{array}{l}\text { Psychological } \\
\text { functioning (anxiety, } \\
\text { depression, hostility) }\end{array}$ & \\
\hline $\begin{array}{l}\text { - The Personal Concerns } \\
\text { Inventory (Offender } \\
\text { Adaptation) } \\
\text { (Sellen et al. 2006) }\end{array}$ & & & Concerns and goals & & & & \\
\hline $\begin{array}{l}\text { - } \quad \text { Level of Service/Case } \\
\text { Management Inventory } \\
\text { (LS/CMI) } \\
\text { (Andrews et al. 2004) }\end{array}$ & Problem denial & & Stages of change & & $\begin{array}{l}\text { Self-confidence/Social } \\
\text { anxiety }\end{array}$ & $\begin{array}{c}\text { Social anxiety/ } \\
\text { Mental } \\
\text { health/Psychopathy }\end{array}$ & $\begin{array}{l}\text { Gender/Culture/ } \\
\text { Ethnicity/ } \\
\text { Intelligence }\end{array}$ \\
\hline
\end{tabular}


Table 1. Cont.

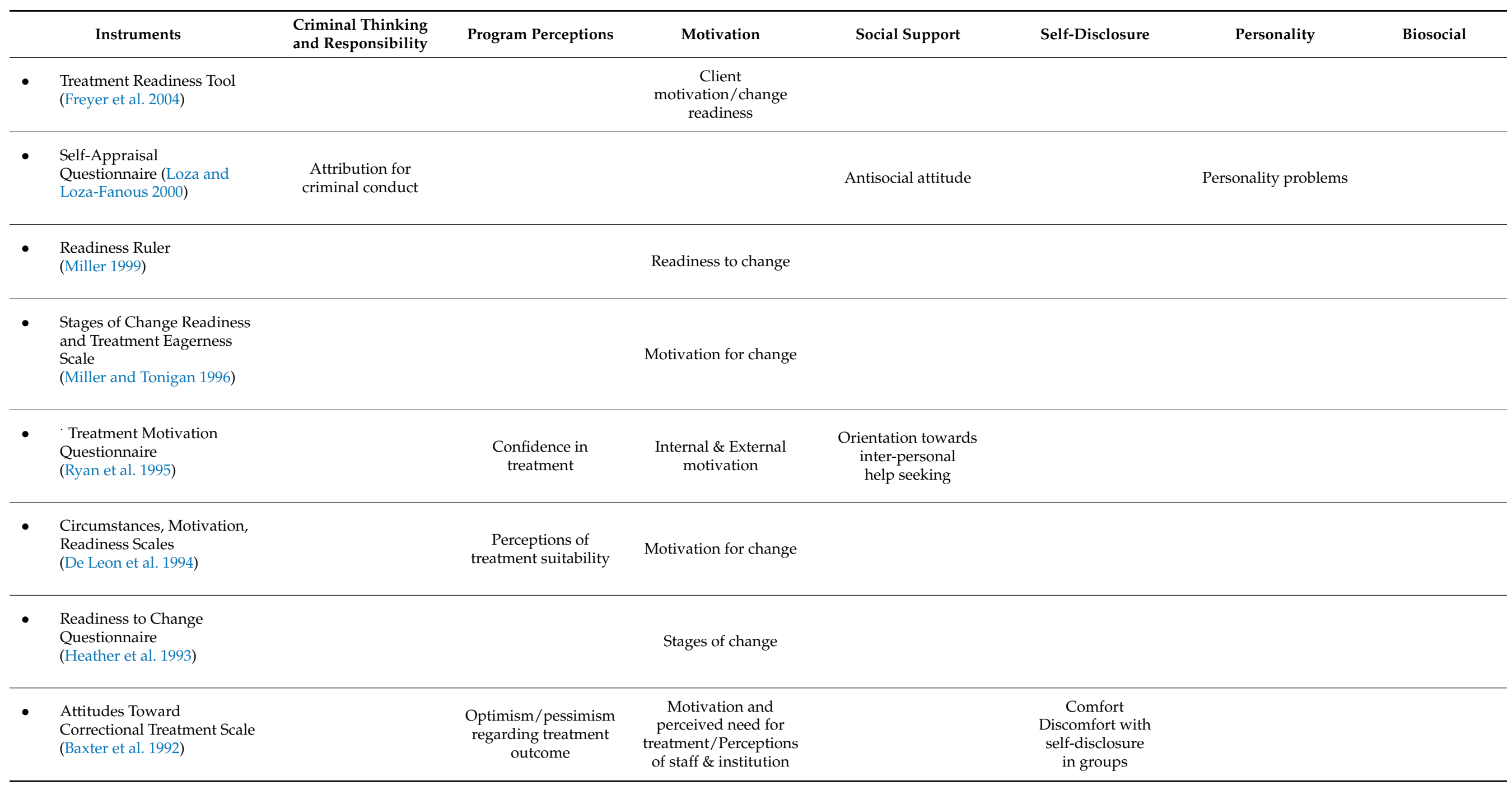


Table 1. Cont.

\begin{tabular}{|c|c|c|c|c|c|c|c|}
\hline Instruments & $\begin{array}{l}\text { Criminal Thinking } \\
\text { and Responsibility }\end{array}$ & Program Perceptions & Motivation & Social Support & Self-Disclosure & Personality & Biosocial \\
\hline $\begin{array}{l}\text { - Client Motivation for } \\
\text { Therapy Scale } \\
\text { (Pelletier et al. 1997) }\end{array}$ & & & $\begin{array}{l}\text { Intrinsic, extrinsic, and } \\
\text { A- motivation }\end{array}$ & & & & \\
\hline $\begin{array}{l}\text { - Jesness Inventory } \\
\quad \text { Classification (Jesness 1988) }\end{array}$ & & & & & Social mal-adjustment & $\begin{array}{l}\text { Personality (cluster } \\
\text { analyses) }\end{array}$ & \\
\hline $\begin{array}{l}\text { Client Management } \\
\text { Classification } \\
\text { (Lerner et al. 1986) }\end{array}$ & Criminal attitudes & & & & & & \\
\hline $\begin{array}{l}\text { - University of Rhode Island } \\
\text { Change Assessment } \\
\text { (McConnaughy et al. 1983) }\end{array}$ & & & Stages of change & & & & \\
\hline
\end{tabular}

Table 2. Responsivity Factors in Child Protection.

Factors
Problem denial is the denial of problems that are indicated by care providers (or other professionals). Clients can minimalize or reject signaled child unsafety, or justify their behavior. Clients can also be unaware of identified problems, or experience them as less severe due to a different frame of reference.
Clinical Treatment Suggestions

- $\quad$ Build on trust before discussing problems

- Allow time for acceptance during frequent contact moments

- Address problems without judgement

- $\quad$ Focus on strengths and possibilities

- Create a 'positive life plan' with concrete steps to reach goals 
Table 2. Cont.

\section{Factors}

Treatment motivation/Willingness to cooperate

Psychological functioning
Think about limitations in mental functioning, or low social adaptability, which consists of conceptual skills (understanding of language, numbers, time, and money), social skills

(communicative skills and solving social problems), and practica

skills (e.g., personal care)

\section{Clinical Treatment Suggestions}

Treatment motivation is the will of a client to start and continue treatment, until a treatment trajectory is completed. Treatment motivation can be insufficient when caregivers do not experience any problems, when there is external pressure (imposed care), when they think a certain treatment is inappropriate, when there when they have low expectations of anxious about youth protective services.

Think about psychopathology as a negative influence on treatment outcomes or the therapeutic relationship, such as (symptoms of) the following disorders: bipolar-mood, anxiety, trauma and stress, depression, autism spectrum disorder, or adhd.
- $\quad$ Cooperate with other involved institutions/care providers

- Keep in touch in-between care facilities

- Prepare client for other care facilities

- Use psychoeducation (explain treatment effects)

- Use motivational communication techniques

- $\quad$ Focus on change, not on static assumptions

- Refer to other treatment settings, consider imposed care

- Provide guidance in referral to mental health care

- Organize interdisciplinary meetings

- Consult diagnostic research (screening)

- Provide psychoeducation to children about parental psychopathology

- Be aware of an instable therapeutic relationship with borderline patients, stay focused on treatment goals and agreements

- Use a practical approach (e.g., visual support, video home training)

- Adapt communication techniques (e.g., simplified translations, repetition, and summarization)

- Consider referral to institutions that are specialized in treating mentally challenged clients

- Consider difficulties with moral reasoning, and incomprehension as an underlying mechanism on client frustrations 
Table 2. Cont.

- Work with an interpreter (e.g., family member, interpreter-phone, or colleague)

- Create a (gender and ethnic) diverse treatment setting

Think about: language, religion, traditional practices, attitudes to

Culture/

Ethnicity gender roles or misogyny, treatment stigma or taboo, and different expectations of appropriate child and parent behavior and

parenting styles. There can also be experienced stressors, such as discrimination, pre-migration or war trauma, immigration, and acculturation. each other to improve therapeutic relationship with a sensitive, understanding, friendly, and open approach without judgement

- Draw a biosocial model including genetic factors, or a personality profile with cultural norms and values together with the client

- Encourage alternative parenting techniques for corporal punishments
Practical barriers/Social support

Think about: transportation issues, day care, work of client, (planned) relocation, or pregnancy.
- $\quad$ Provide financial support (e.g., emergency funds)

- Be flexible (e.g., home visitation and 'off the clock' availability)

- Use an outreaching approach, provide guidance in referral to social welfare institutions

- Apply a multisystem/contextual approach for involving social networks

- $\quad$ List priorities

- $\quad$ Provide resocialization possibilities and job coaching
Barriers to treatment/ intervention type
Individual therapy can be more appropriate when parents cannot function in groups because of personal problems, or due to the inability to interact socially.
- Consider a client's cognitive functioning and disruptive behavior in discussing appropriateness of group therapy 


\subsubsection{Treatment Motivation/Willingness to Cooperate}

Several participants mentioned that motivation can be misinterpreted when there is unfamiliarity with child protection services or anxiety about imposed measures ("Some clients associate youth protection services with the idea: They will take my child away, I am going to lose my child."), or inability of clients ("If someone refuses treatment, you might think the client does not want to be treated, but sometimes the client cannot be treated, because he is still heavily addicted" or, "If you are very depressed, you might want to, but you cannot make it work."). Clients can also be 'tired of treatment', or demotivated by long waiting lists.

Treatment Suggestions. Some participants mentioned that they refer clients to other institutions when there is no treatment motivation, including imposed sanctions. Others said that imposed care may lead to even less motivation. One participant also mentioned that institutions should cooperate/communicate better. Furthermore, it can be important to keep in contact when clients are 'in between' treatment settings/institutions, and that they are prepared carefully for other treatment settings. Other suggestions for enhancing treatment motivation were psycho-education, motivational communication techniques, clarity and transparency to reach agreement, explanation of treatment effects, and focusing on change instead of (one's own) static assumptions.

\subsubsection{Psychological Functioning}

Some participants suggested that personality disorders are important to take into account, because these disorders can affect the therapeutic relationship in a negative way ("When it comes to adults, personality problems are the most common, especially, borderline is a huge barrier to building up a therapeutic relationship.").

Treatment Suggestions. Providing guidance in referral to mental health care was mentioned the most. Other suggestions were: interdisciplinary meetings, diagnostic research, family system therapy, and psycho-education for children about parental psychological problems. Regarding borderline patients, the care provider should be aware of an instable therapeutic relationship.

\subsubsection{Social Support/Practical Barriers}

'Financial problems' were recognizable for participants, and mentioned as an important cause for other problems ("Being in debt is such a heavy burden for parents, that it gets in the way of good parenting, because parents become emotional unavailable due to the stress it causes."), or ("What I have heard a lot is: 'I want to come, but I do not have the money', or 'I wish I could talk to you in person, but I cannot afford public transport'. It is not considered enough that someone might actually want help, but simply does not have the resources for it."). Other important barriers were also mentioned: parental divorce in combination with housing problems ("When parents get divorced, they sometimes still have to live together in the same house for more than a year, which causes a lot of stress and tension."), homelessness, absence of social contacts, and absence of a permanent residence permit. Finally, participants suggested that practical barriers such as financial problems and barriers to treatment type (group/individual) should be separated.

Treatment Suggestions. First, providing financial support, for example from emergency funds, was suggested. Second, participants emphasized the importance of flexible working hours, including home visitations and digital availability (e.g., Whatsap). Third, participants mentioned that the form of treatment, for example group therapy, should be appropriate to a client's cognitive functioning and disruptive behavior.

\subsubsection{Cognitive Abilities}

Some participants considered a standardized IQ-level description as too theoretical, and suggested a more practical approach, for example 'mentally challenged'. Another comment was that a higher intelligence of the child compared to the parents should also be signaled ("What makes it complicated is when a child is much smarter than its parents, 
especially for children aged ten and over, because this can lead to an undesirable role reversal."). The inclusion of social adjustment capacity in the description was considered relevant by the participants.

Treatment Suggestions. Participants indicated that this specific client factor could be better addressed within their treatment approaches. For example, one participant admitted that it is quite difficult to use appropriate communication techniques, and another professional mentioned that clients are easily verbally overrated. Referral to a more specialized institution was therefore a recurring suggestion, but some participants already applied appropriate treatment modules at their own care facility. A frequently mentioned treatment suggestion was providing a more practical approach, using visual support (e.g., video home training). Verbal adaptations were also mentioned, for example using simplified translations and specific communication techniques (e.g., repetition, summarization).

\subsubsection{Culture/Ethnicity}

Important proposed adjustments to the description were inclusion of war trauma, religion, attitudes about gender roles, misogyny, and taboos (shame about accepting external help). Another comment was that there are many differences between and within cultures, which might be difficult to categorize under the same heading. ("A care provider and a client may have the same ethnical background, but still differ in standards and values. For example, suppose that I am Turkish, but a Turkish family still does not want my help, because they are ashamed of getting help.").

Treatment Suggestions. Using an interpreter (e.g., a family member, or a colleague with the same ethnicity as the client) during treatment sessions was suggested. Furthermore, suggestions were made on addressing diversity in the treatment environment (i.e., ethnic diversity and gender diversity). A conversation about each other's values may be important for improving the therapeutic relationship. Such a conversation should be approached with a sensitive, friendly and open attitude without judgement. Another suggestion was to create a biosocial model including genetic factors, or a personality profile including norms and values together with the client. Last, hitting a child as a punishment technique can be more common within specific cultures, in which case alternative parenting techniques should be discussed and encouraged.

\section{Discussion}

The aim of this study was to provide an overview of relevant responsivity factors in child protection. The overview was based on a literature review on responsivity factors in forensic care, and adjusted to child protection based on interviews with clinical professionals. This study identified seven responsivity factors (i.e., problem denial, treatment motivation, psychological functioning, cognitive abilities, culture/ethnicity, practical barriers/social support, and barriers to intervention type) in an intervention paradigm that builds on the broader criminogenic Risks Needs Responsivity (RNR)-framework (Bonta and Andrews 2016). In addition, clinical professionals provided treatment recommendations to target responsivity factors in order to enhance caregivers' abilities to succeed in treatment.

Due to the widely diverging views on how responsivity should be defined, there is no consensus in the scientific literature on how responsivity factors should be operationalized and assessed in criminal practice (Hubbard 2007). In the first part of this study, we therefore addressed this gap by providing an overview of the operationalization of the responsivity principle in forensic treatment based on a literature review. Second, we assessed the clinical relevance of these identified responsivity factors for child protection practices by interviewing clinical professionals. At first, most child protection professionals were not yet familiar with the concept of responsivity from the RNR-framework in forensic care (Bonta and Andrews 2016). However, after the introduction of the Responsivity principle, the professionals suggested many factors (e.g., cognitive abilities, ethnicity/culture) corresponding to the identified factors from the literature search. Furthermore, after presenting 
the overview of identified responsivity factors related to caregiver characteristics, all professionals affirmed the importance of targeting those factors in child protection services to optimize treatment circumstances.

The results in this study indicate that personalizing treatment circumstances to specific characteristics of caregivers involved in child protection services may be promising for enhancing treatment engagement, just as in criminal practice (Wormith and Olver 2002). For instance, one professional stressed the risk of an instable therapeutic relationship because of a borderline personality disorder, which is known to be related to a high client attrition rate in interventions (Wnuk et al. 2013; Yeomans et al. 1994). Additionally, 'cognitive ability', the most frequently mentioned responsivity factor by the interviewed practitioners, can also increase the risk for intervention attrition in child welfare systems due to a mismatch between client and intervention style (Van Yperen et al. 2003). Remarkably, (parental) cognitive impairment was the only factor about which several professionals acknowledged that it should be more carefully addressed within their treatment settings. This result is in line with the urgent need of agencies which specialize in supporting parents with cognitive impairments, especially because children of parents with cognitive impairments are over-represented in child maltreatment investigations and out-of-home care (McConnell et al. 2011). Further, in their latest research, Bonta and Andrews (2016) argue that motivation should be increased to prevent treatment dropout. Just as in criminal practice, working with unwilling or involuntary clients in child protection services is challenging, and needs to be addressed with an appropriate approach (Turney 2012).

For example, caregivers may not be unwilling to cooperate, but rather are unaware of their problems, or afraid of a practitioner's power to remove their children (Bartelink et al. 2018). Some practitioners may overlook such relevant information, because of a tendency to be biased to information that confirms their previous judgements (Bartelink et al. 2015). Furthermore, practical barriers to participation, such as lack of transportation and money, reflect pressing needs of parents that unfortunately tend to be inadequately addressed by child welfare services (Kemp et al. 2008). The provided overview in this study supports the awareness of such caregiver characteristics, and facilitates personalized treatment using a fitting approach.

\subsection{Limitations and Future Research}

Several limitations of the present study need to be discussed. First, although our structured literature search was extensive, we may have missed studies on the assessment of responsivity factors. For example, relevant studies may have not been indexed with keywords derived from the "responsivity factor" concept, making it more difficult to identify these studies. Nevertheless, as 21 instruments assessing a total of 50 responsivity factors were included, it may be assumed that the sample of included studies was sufficiently representative of all primary studies available on responsivity assessment. Second, the overview of responsivity factors in this study is related to caregiver characteristics, and therefore does not include all responsivity factors from the literature search on responsivity assessment and the interviews. For example, qualities of care providers that influence the therapeutic relationship between client and therapist are also important to consider in both criminal practice and child protection services (Andrews et al. 2011; Kemp et al. 2008).

Lastly, as Skeem et al. (2015) rightly indicated, generalizability of the responsivity principle from criminal practice to a new population with unique characteristics, such as families in child protection, should be done cautiously. Although the results of this study revealed substantial overlap in responsivity factors between criminal practice and child protection services, the fruitfulness of the RNR framework in child protection still needs empirical support. Therefore, future research should focus on the effects of applying the RNR principles to child welfare. Further research should also focus on determining the best approach to treatment optimization after responsivity factors have been assessed. This study provided expert-based knowledge on such treatment tailoring techniques to address responsivity factors, but this can be substantiated with research-based insights 
into effective treatment techniques. For example, the responsivity factor 'motivation' can be addressed with motivational interviewing, which may lead to improved retention in treatment (Andrews et al. 2011; McMurran 2009). This knowledge can also be derived from current treatment techniques in protocolled intervention programs. For example, in multisystemic therapy much attention is already given to a personalized 'fit' of treatment goals and techniques based on clinical identified risk factors if family problems, such as a lack of treatment motivation (MST-The Netherlands 2020).

\subsection{Clinical Implications}

Several important responsivity factors can be screened in the decision-making process of clinical professionals who need to address these factors before or in parallel to intervention programs. Practitioners in child protection may rely on intuitive decision-making, which makes them vulnerable to overlook relevant information (Bartelink et al. 2018). Using checklists and guidelines are essential strategies in avoiding possible bias due to intuitive practitioner reasoning (Munro 1999). An overview of responsivity factors supports structured decision-making, and may therefore prevent such bias.

Primarily, introducing the responsivity principle to child protection is necessary to enable personalized treatment according to all three RNR principles (Andrews et al. 1990). As we know from criminal practice, interventions that adhere to all three principles of the RNR framework reduce offender recidivism most effectively (e.g., Andrews et al. 1990; Hanson et al. 2009). Therefore, the results of this study can strengthen the benefits of previously developed tools for risk and need assessment in child welfare (e.g., Van der Put et al. 2016a, 2018b; De Ruiter et al. 2012).

\section{Conclusions}

Recent studies pointed towards the value of implementing the Risk and Need principles of the Risk Need Responsivity model (Andrews et al. 1990) in child protection services to enhance the effectiveness of treatment for reducing the risk of (recurrence of) child maltreatment (e.g., Van der Put et al. 2016b, 2018a). However, studies on the implementation of the Responsivity principle in the field of child protection were not yet available. Therefore, the present study was aimed at introducing the Responsivity principle of the RNR-model into the field of child protection. To apply this principle from criminal practice to child protection, this study identified responsivity factors in criminal practice based on a literature review, and examined the clinical relevance of these factors by conducting a qualitative case study among child protection professionals. This resulted in an overview of seven responsivity factors that are all related to caregiver characteristics: problem denial, motivation to cooperate with treatment, psychological problems, cognitive abilities, cultural background, practical barriers such as financial problems and social support, and barriers to specific treatment types such as group therapy. In addition, clinical professionals provided treatment recommendations for targeting these responsivity factors with the aim of enhancing caregivers' abilities to succeed in treatment. The results support practitioners working in the field of child protection adhering to the responsivity principle of the Risk Need Responsivity framework (Andrews et al. 1990) by identifying responsivity factors that may interfere with clients' abilities to succeed in treatment (Cunningham and Henggeler 1999; Hubbard 2007). This is important, as it is empirically supported that interventions which are better tailored to clients' responsivity characteristics yield better outcomes (Andrews et al. 1990; Hanson et al. 2009). Therefore, it may be expected that introducing the Responsivity principle in child protection boosts optimization of treatment circumstances, and hopefully, intervention effectiveness. 
Author Contributions: Conceptualization, C.E.v.d.P., A.M.E.B., and M.A.; methodology, A.M.E.B., C.E.v.d.P., and M.A.; validation, A.M.E.B., C.E.v.d.P. and M.A.; formal analysis, A.M.E.B.; investigation, A.M.E.B.; resources, A.M.E.B. and C.E.v.d.P.; data curation, A.M.E.B.; writing-original draft preparation, A.M.E.B.; writing—review and editing, C.E.v.d.P., M.A., G.O., G.J.J.M.S., and A.M.E.B.; supervision, C.E.v.d.P., G.O., G.J.J.M.S., and M.A.; project administration, C.E.v.d.P.; funding acquisition, C.E.v.d.P. All authors have read and agreed to the published version of the manuscript.

Funding: This research was funded by ZonMw, grant number 741100002.

Institutional Review Board Statement: The data collection in this study is approved by the Ethics Committee of the University of Amsterdam (Faculty of Social and Behavioral Sciences) (2018-CDE-9629).

Informed Consent Statement: Informed consent was obtained from alle subjects involved in the study.

Data Availability Statement: Not applicable.

Conflicts of Interest: The authors declare no conflict of interest.

\section{References}

Andrews, Donald. A., James Bonta, and Robert. D. Hoge. 1990. Classification for effective rehabilitation: Rediscovering psychology. Criminal Justice and Behavior 17: 19-52. [CrossRef]

Andrews, Donald. A., James Bonta, and Stephen Wormith. 2004. Level of Service/Case Management Inventory (LS/CMI). Toronto: Multi-Health Systems Inc.

Andrews, Donald. A., James Bonta, and Stephen Wormith. 2011. The Risk-Need-Responsivity (RNR) Model: Does adding the Good Lives Model contribute to effective crime prevention? Criminal Justice and Behavior 38: 735-55. [CrossRef]

Bartelink, Cora, Tom A. Van Yperen, and Ingrid J. Ten Berge. 2015. Deciding on child maltreatment: A literature review on methods that improve decision-making. Child Abuse and Neglect 49: 142-53. [CrossRef] [PubMed]

Bartelink, Cora, Erik J. Knorth, Mónica López López, Carien Koopmans, Ingrid J. Ten Berge, Cilia L. M. Witteman, and Tom A. Van Yperen. 2018. Reasons for placement decisions in a case of suspected child abuse: The role of reasoning, work experience and attitudes in decision-making. Child Abuse and Neglect 83: 129-41. [CrossRef]

Baxter, David. I., M. Burchill, and M. Tweedale. 1992. The Attitudes towards Correctional Treatment Scale; Merrickville: Ontario Ministry of Correctional Services.

Begun, Audrey L., Michael J. Brondino, Daniel Bolt, Benjamin Weinstein, Terri Strodthoff, and Gene Shelley. 2008. The Revised Safe at Home Instrument for Assessing Readiness to Change Intimate Partner Violence. Violence and Victims 23: 508-24. [CrossRef] [PubMed]

Belsky, Jay. 1980. Child maltreatment: An ecological integration. American Psychologist 35: 320-35. [CrossRef]

Belsky, Jay. 1984. The determinants of parenting: A process model. Child Development 55: 83-96. [CrossRef]

Boeije, Hennie. 2014. Analyseren in Kwalitatief Onderzoek. Amsterdam: Boom.

Bonta, James, and Donald. A. Andrews. 2007. Risk-Need-Responsivity Model for Offender Assessment and Rehabilitation: User Report 2007-2006. Ottawa: Public Safety Canada.

Bonta, James, and Donald. A. Andrews. 2016. The Psychology of Criminal Conduct, 6th ed. New York: Routledge.

Bronfenbrenner, Urie. 1979. The Ecology of Human Development: Experiments by Nature and Design. Cambridge: Harvard University Press.

Casey, Sharon, Andrew Day, Kevin Howells, and Tony Ward. 2007. Assessing suitability for offender rehabilitation: Development and validation of the Treatment Readiness Questionnaire. Criminal Justice and Behavior 34: 1427-40. [CrossRef]

Cicchetti, Dante, and Vicki Carlson, eds. 1989. Child Maltreatment. Cambridge: Cambridge University Press.

Cicchetti, Dante, and Ross Rizley. 1981. Developmental perspectives on etiology, intergenerational transmission and sequelae of child maltreatment. New Directions for Child and Adolescent Development 11: 31-56. [CrossRef]

Covell, Christmas N., and Jennifer G. Wheeler. 2011. Application of the responsivity principle to treatment of sexual offense behavior. Journal of Forensic Psychology Practice 11: 61-72. [CrossRef]

Cunningham, Phillippe B., and Scott W. Henggeler. 1999. Engaging multiproblem families in treatment: Lessons learned throughout the development of Multisystemic Therapy. Family Process 38: 265-81. [CrossRef]

Dawson, Kari, and Marianne Berry. 2002. Engaging families in child welfare services: An evidence based approach to best practice. Child Welfare 81: 293-17.

Day, Andrew, Kevin Howells, Sharon Casey, Tony Ward, Jemma C. Chambers, and Astrid Birgden. 2009. Assessing treatment readiness in violent offenders. Journal of Interpersonal Violence 24: 618-35. [CrossRef]

De Leon, George, Gerald Melnick, David Kressel, and Nancy Jainchill. 1994. Circumstances, Motivation, Readiness, and Suitability (The CMRS Scales): Predicting Retention in Therapeutic Community Treatment. Drug Alcohol Abuse 20: 495-515. [CrossRef]

De Ruiter, Corine, Martin Hildebrand, and Steven Van der Hoorn. 2012. Gestructureerde risicotaxatie bij kindermishandeling: De Child Abuse Risk Evaluation-Nederlandse versie (CARE-NL). GZ-Psychologie 4: 10-17. [CrossRef] 
Drieschner, Klaus Heinrich, and Anne Boomsma. 2008. The Treatment Engagement Rating scale (TER) for forensic outpatient treatment: Description, psychometric properties, and norms. Psychology, Crime, and Law 14: 299-315. [CrossRef]

English, Diana J., Richard Thompson, J. Christopher Graham, and Ernestine C. Briggs. 2005. Toward a definition of neglect in young children. Child Maltreatment 10: 190-206. [CrossRef] [PubMed]

Euser, Saskia, Lenneke R. A. Alink, Marije Stoltenborgh, Marian J. Bakermans-Kranenburg, and Marinus van IJzendoorn. 2015. A gloomy picture: A meta-analysis of randomized controlled trials reveals disappointing effectiveness of programs aiming at preventing child maltreatment. BMC Public Health 15: 1068. [CrossRef] [PubMed]

Folger, Susan F., and Margaret O'Dougherty Wright. 2013. Altering risk following child maltreatment: Family and friend support as protective factors. Journal of Family Violence 28: 325-37. [CrossRef]

Freyer, Jennis, J. Scott Tonigan, Stefan Keller, Ulrich John, Hans-Jürgen Rumpf, and Ulfert Hapke. 2004. Readiness to change versus readiness to seek help for alcohol problems: The development of the Treatment Readiness Tool (TReaT). Journal of Studies on Alcohol 65: 801-9. [CrossRef] [PubMed]

Garner, Bryan R., Kevin Knight, Patrick M. Flynn, Janis T. Morey, and D. Dwayne Simpson. 2007. Measuring offender attributes and engagement in treatment using the client evaluation of self and treatment. Criminal Justice and Behavior 34: 1113-30. [CrossRef]

Gilbert, Ruth, Cathy Spatz Widom, Kevin Browne, David Fergusson, Elspeth Webb, and Staffan Janson. 2009. Burden and consequences of child maltreatment in high-income countries. The Lancet 373: 68-81. [CrossRef]

Guest, Greg, Arwen Bunce, and Laura Johnson. 2006. How many interviews are enough? An experiment with data saturation and variability. Field Methods 18: 59-82. [CrossRef]

Hanson, R. Karl, Guy Bourgon, Leslie Helmus, and Shannon Hodgson. 2009. The principles of effective correctional treatment also apply to sexual offenders: A meta-analysis. Criminal Justice and Behavior 36: 865-91. [CrossRef]

Heather, Nick, Stephen Rollnick, and Alison Bell. 1993. Predictive validity of the Readiness to Change Questionnaire. Addiction 8: 1667-77. [CrossRef] [PubMed]

Howells, Kevin, and Andrew Day. 2003. Readiness for anger management: Clinical and theoretical issues. Clinical Psychology Review 23: 219-337. [CrossRef]

Howells, Kevin, and Andrew Day. 2007. Readiness for treatment in high risk offenders with personality disorders. Psychology, Crime and Law 31: 47-56. [CrossRef]

Hubbard, Dana J. 2007. Getting the most out of correctional treatment: Testing the responsivity principle on male and female offenders. Federal Probation 71: 2-8.

Jesness, Carl F. 1988. The Jesness Inventory Classification. Criminal Justice and Behavior 15: 78-91. [CrossRef]

Kemp, Susan P., Maureen O. Marcenko, Kimberly Hoagwood, and William Vesneski. 2008. Engaging parents in child welfare services: Bridging family needs and child welfare mandates. Child Welfare 88: 101-26.

Lerner, Kenneth, Gary Arling, and S. Christopher Baird. 1986. Client Management Classification Strategies for Case Supervision. Crime and Delinquency 32: 254-71. [CrossRef]

Looman, Jan, Ida Dickie, and Jeffrey Abracen. 2005. Responsivity issues in the treatment of sexual offenders. Trauma, Violence, and Abuse 6: 330-53. [CrossRef] [PubMed]

Loza, Wagdy, and Amel Loza-Fanous. 2000. Predictive Validity of the Self-Appraisal Questionnaire (SAQ): A tool for assessing violent and nonviolent release failures. Journal of Interpersonal Violence 15: 1183-91. [CrossRef]

Loza, Wagdy, Gurmeet Dhaliwal, Daryl G. Kroner, and Amel Loza-Fanous. 2000. Reliability, construct, and concurrent validities of the self-appraisal questionnaire: A tool for assessing violent and nonviolent recidivism. Criminal Justice and Behavior 27: 356-74. [CrossRef]

McConnaughy, Eileen A., Carlo C. DiClemente, James O. Prochaska, and Wayne F. Velicer. 1983. Stages of change in psychotherapy: Measurement and sample profiles. Psychotherapy: Theory, Research, and Practice 20: 368-75. [CrossRef]

McConnell, David, Maurice Feldman, Marjorie Aunos, and Narasimha Prasad. 2011. Parental cognitive impairment and child maltreatment in Canada. Child Abuse and Neglect 35: 621-32. [CrossRef]

McMurran, Mary. 2009. Motivational interviewing with offenders: A systematic review. Legal and Criminological Psychology 14: 83-100. [CrossRef]

Miller, William R. 1999. Enhancing Motivation for Change in Substance Abuse Treatment; Rockville: U.S. Department of Health and Human Services.

Miller, William R., and J. Scott Tonigan. 1996. Assessing drinkers' motivation for change: The Stages of Change Readiness and Treatment Eagerness Scale (SOCRATES). Psychology of Addictive Behaviors 10: 81-89. [CrossRef]

Mossière, Annik, and Ralph Serin. 2013. A critique of models and measures of treatment readiness in offenders. Aggression and Violent Behavior 19: 383-89. [CrossRef]

MST-The Netherlands. 2020. Multisystemic Therapy. Available online: https://www.nji.nl/nl/Databank/Databank-EffectieveJeugdinterventies/Erkende-interventies-Multisysteem-Therapie-(MST) (accessed on 1 September 2020).

Mulder, Tim M., Kimberly C. Kuiper, Claudia E. van der Put, Geert-Jan J. M. Stams, and Mark Assink. 2018. Risk factors for child neglect: A meta-analytic review. Child Abuse and Neglect 77: 198-210. [CrossRef]

Munro, Eileen. 1999. Common errors of reasoning in child protection work. Child Abuse and Neglect 23: 745-58. [CrossRef]

$\mathrm{Ng}$, Mei Yi, and John R. Weisz. 2016. Annual research review: Building a science of personalized intervention for youth mental health Journal of Child Psychology and Psychiatry 57: 216-36. [CrossRef] 
Ogloff, James R. P., and Michael R. Davis. 2004. Advances in offender assessment and rehabilitation: Contributions of the risk-needsresponsivity approach. Psychology, Crime, and Law 10: 229-42. [CrossRef]

Pelletier, Luc G., Kim M. Tuson, and Najwa K. Haddad. 1997. Client Motivation for Therapy Scale: A measure of intrinsic motivation, extrinsic motivation, and amotivation for therapy. Journal of Personality Assessment 68: 414-35. [CrossRef]

Platt, Dendy. 2012. Understanding parental engagement with child welfare services: An integrated model. Child and Family Social Work 17: 138-48. [CrossRef]

Polaschek, Devon. L. L. 2012. An appraisal of the risk-need-responsivity (RNR) model of offender rehabilitation and its application in correctional treatment. Legal and Criminological Psychology 17: 1-17. [CrossRef]

Ryan, Richard M., Robert W. Plant, and Stephanie O'Malley. 1995. Initial motivations for alcohol treatment: Relations with patient characteristics, treatment involvement, and dropout. Addictive Behaviors 20: 279-97. [CrossRef]

Sellen, Joselyn L., Mary McMurran, W. Miles Cox, Eleni Theodosi, and Eric Klinger. 2006. The Personal Concerns Inventory (Offender Adaptation) measuring and enhancing motivation to change. International Journal of Offender Therapy and Comparative Criminology 50: 294-305. [CrossRef]

Simpson, D. Dwayne, George W. Joe, Kevin Knight, Grace A. Rowan-Szal, and Julie S. Gray. 2012. Texas Christian University (TCU) Short Forms for assessing client needs and functioning in addiction treatment. Journal of Offender Rehabilitation 51: 34-56. [CrossRef]

Skeem, Jennifer L., Henry J. Steadman, and Sarah M. Manchak. 2015. Applicability of the Risk-Need Responsivity Model to persons with mental illness involved in the criminal justice system. Psychiatric Services 66: 916-22. [CrossRef]

Smith, Paula, Paul Gendreau, and Kristin Swartz. 2009. Validating the principles of effective intervention: A systematic review of the contributions of meta-analysis in the field of corrections. Victims and Offenders 4: 148-69. [CrossRef]

Stoltenborgh, Marije, Marian J. Bakermans-Kranenburg, Lenneke R. A. Alink, and Marinus H. van IJzendoorn. 2015. The Prevalence of child maltreatment across the globe: Review of a series of meta-analyses. Child Abuse Review 24: 37-50. [CrossRef]

Stouthamer-Loeber, Magda, Rolf Loeber, Evelyn Wei, David P. Farrington, and Per-Olof H. Wikström. 2002. Risk and promotive effects in the explanation of persistent serious delinquency in boys. Journal of Consulting and Clinical Psychology 70: 11-23. [CrossRef]

Taxman, Faye S. 2014. Second generation of RNR: The importance of systematic responsivity in expanding core principles of responsivity. Federal Probation 78: 32-40.

Turney, Danielle. 2012. A relationship-based approach to engaging involuntary clients: The contribution of recognition theory. Child and Family Social Work 17: 149-59. [CrossRef]

Van der Put, Claudia E., Jo Hermanns, and Frouke Sondeijker. 2016a. Inschatten van het risico op kindermishandeling bij aanvang van gezinsinterventies: De predictieve validiteit van de Nederlandse versie van de California Family Risk Assessment (CFRA). Kind en Adolescent 37: 213-29. [CrossRef]

Van der Put, Claudia, Mark Assink, and Geert Jan Stams. 2016b. Predicting relapse of problematic child-rearing situations. Children and Youth Services Review 61: 288-95. [CrossRef]

Van der Put, Claudia E., Mark Assink, Jeanne Gubbels, and Noëlle F. Boekhout van Solinge. 2018a. Identifying effective components of child maltreatment interventions: A meta-analysis. Clinical Child and Family Psychology Review 21: 171-202. [CrossRef]

Van der Put, Claudia, Mark Assink, Jeanne Gubbels, Judith van Lent, and Geert Jan Stams. 2018b. Risico op Kindermishandeling verlagen met ARIJ-NEEDS. Kind en Adolescent Praktijk 3: 16-24. [CrossRef]

Van Yperen, Tom, Yvonne Booy, and Marie-Christine van der Veldt. 2003. Vraaggerichte Hulp, Motivatie en Effectiviteit Jeugdzorg. Utrecht: NIZW Jeugd.

Van Yperen, Tom, Jan Willem Veerman, and Bas Bijl. 2017. Zicht op Effectiviteit. Handboek voor Resultaatgericht Ontwikkeling van Interventies in de Jeugdzorg. Rotterdam: Uitgeverij Lemniscaat b.v.

Vlahovicova, Kristina, Gerardo. J. Melendez-Torres, Patty Leijten, Wendy Knerr, and Frances Gardner. 2017. Parenting programs for the prevention of child physical abuse recurrence: A systematic review and meta-analysis. Clinical Child and Family Psychology Review 20: 351-65. [CrossRef] [PubMed]

Ward, Tony, Joseph Melser, and Pamela M. Yates. 2007. Reconstructing the Risk-Need-Responsivity model: A theoretical elaboration and evaluation. Aggression and Violent Behavior 12: 208-28. [CrossRef]

Weisz, John. R. 2014. Building robust psychotherapies for children and adolescents. Perspectives on Psychological Science 9: 81-84. [CrossRef]

Wnuk, Susan, Shelley McMain, Paul S. Links, Liat Habinski, Joshua Murray, and Tim Guimond. 2013. Factors related to dropout from treatment in two outpatient treatments for borderline personality disorder. Journal of Personality Disorders 27: 716-26. [CrossRef] [PubMed]

Wormith, J. Stephen, and Mark E. Olver. 2002. Offender treatment attrition and its relationship with risk, responsivity, and recidivism. Criminal Justice and Behavior 29: 447-71. [CrossRef]

Yeomans, Frank E., Janice Gutfreund, Michael A. Selzer, John F. Clarkin, James W. Hull, and Thomas E. Smith. 1994. Factors related to drop-outs by borderline patients. Journal of Psychotherapy Practice and Research 3: 16-24. 